\title{
Phase Synchronicity of $\mu$-Rhythm Determines Efficacy of Interhemispheric Communication Between Human Motor Cortices
}

\author{
Maria-Ioanna Stefanou, ${ }^{\star}$ Debora Desideri, ${ }^{\star} \odot$ Paolo Belardinelli, Christoph Zrenner, and $\odot$ Ulf Ziemann \\ Department of Neurology and Stroke and Hertie Institute for Clinical Brain Research, Eberhard-Karls University of Tübingen, 72076 Tübingen, Germany
}

The theory of communication through coherence predicts that effective connectivity between nodes in a distributed oscillating neuronal network depends on their instantaneous excitability state and phase synchronicity (Fries, 2005). Here, we tested this prediction by using state-dependent millisecond-resolved real-time electroencephalography-triggered dual-coil transcranial magnetic stimulation (EEGTMS) (Zrenner et al., 2018) to target the EEG-negative (high-excitability state) versus EEG-positive peak (low-excitability state) of the sensorimotor $\mu$-rhythm in the left (conditioning) and right (test) motor cortex (M1) of 16 healthy human subjects ( 9 female, 7 male). Effective connectivity was tested by short-interval interhemispheric inhibition (SIHI); that is, the inhibitory effect of the conditioning TMS pulse given 10-12 ms before the test pulse on the test motor-evoked potential. We compared the four possible combinations of excitability states (negative peak, positive peak) and phase relations (in-phase, out-of-phase) of the $\mu$-rhythm in the conditioning and test M1 and a random phase condition. Strongest SIHI was found when the two M1 were in phase for the high-excitability state (negative peak of the $\mu$-rhythm), whereas the weakest SIHI occurred when they were out of phase and the conditioning M1 was in the low-excitability state (positive peak). Phase synchronicity contributed significantly to SIHI variation, with stronger SIHI in the in-phase than out-ofphase conditions. These findings are in exact accord with the predictions of the theory of communication through coherence. They open a translational route for highly effective modification of brain connections by repetitive stimulation at instants in time when nodes in the network are phase synchronized and excitable.

Key words: communication through coherence; EEG-TMS; effective cortico-cortical connectivity; human; interhemispheric communication; motor cortex

\section{Significance Statement}

The theory of communication through coherence predicts that effective connectivity between nodes in distributed oscillating brain networks depends on their instantaneous excitability and phase relation. We tested this hypothesis in healthy human subjects by real-time analysis of brain states by electroencephalography in combination with transcranial magnetic stimulation of left and right motor cortex. We found that short-interval interhemispheric inhibition, a marker of interhemispheric effective connectivity, was maximally expressed when the two motor cortices were in phase for a high-excitability state (the trough of the sensorimotor $\mu$-rhythm). We conclude that findings are consistent with the theory of communication through coherence. They open a translational route to highly effectively modify brain connections by repetitive stimulation at instants in time of phasesynchronized high-excitability states.

\section{Introduction}

Neuronal assemblies in the brain oscillate and thereby undergo rhythmic fluctuations of excitation and inhibition (Buzsáki and

Received June 10, 2018; revised Oct. 14, 2018; accepted 0ct. 15, 2018

Author contributions: M.I.S., D.D., P.B., and C.Z. wrote the first draft of the paper; U.Z. edited the paper; U.Z. designed research; M.-I.S., D.D., P.B., and C.Z. performed research; M.I.S., D.D., P.B., C.Z., and U.Z. analyzed data; U.Z. wrote the paper.

This work was supported by the Deutsche Forschungsgemeinschaft (Grant ZI 542/7-1 to U.Z.), the Federal Ministry of Education and Research (BMBF MOTOR-BIC Grant to U.Z.), and the University of Tübingen (Fortüne Junior Grant 2287-0-0 to C.Z.).
Draguhn, 2004; Jensen and Mazaheri, 2010). The theory of communication through coherence (CTC) (Fries, 2005, 2015) predicts that coherently oscillating neuronal assemblies in distributed

The authors declare no competing financial interests.

*M.I.S. and D.D. contributed equally to this work.

Correspondence should be addressed to Dr. Ulf Ziemann, Department of Neurology and Stroke and Hertie Institute for Clinical Brain Research, Eberhard-Karls University of Tübingen, Hoppe-Seyler-Str. 3, 72076 Tübingen, Germany. E-mail: ulf.ziemann@uni-tuebingen.de.

https://doi.org/10.1523/JNEUROSCI.1470-18.2018

Copyright $\odot 2018$ the authors $\quad 0270-6474 / 18 / 3810525-10 \$ 15.00 / 0$ 
cortical networks interact effectively in synchronized states of high excitability (Womelsdorf et al., 2007). CTC is considered fundamental for all higher cognitive and sensorimotor brain functions (Singer, 1999; Varela et al., 2001; Uhlhaas and Singer, 2010). Early experimental evidence for CTC in bihemispheric networks came from studies in cats that revealed that interhemispheric oscillatory synchronization between homologous neural assemblies in primary visual cortex is critical for the binding of distributed features of neural information in the two visual hemifields (Engel et al., 1991). In the motor domain, 20-40 Hz oscillations in monkey primary motor cortices (M1) of the two hemispheres transiently synchronize during bimanual and unimanual motor tasks (Murthy and Fetz, 1996) and, in human motor cortex, paired-pulse transcranial magnetic stimulation (TMS) experiments revealed that inhibitory motor signals are transmitted in beta bursts in large-scale motor cortical networks for inhibitory motor control (Picazio et al., 2014).

Here, we sought to test one of the core predictions of the CTC theory that effective communication critically depends on the phase relation between neuronal assemblies, for inhibitory interhemispheric motor activity at the systems level in humans. Interhemispheric effective connectivity can be measured by a dual-coil paired-pulse TMS protocol that results in short-interval interhemispheric inhibition (SIHI) of motor evoked potentials (MEPs) if the two pulses are given to the conditioning and test $\mathrm{M} 1 \sim 10 \mathrm{~ms}$ apart (Ferbert et al., 1992; Daskalakis et al., 2002). For testing phase relations of the ongoing sensorimotor $\mu$-rhythm, we made use of a recently developed technique that allows analysis of $\mu$-rhythm phase with electroencephalography (EEG) in real time and triggering of TMS pulses at prespecified phase (Zrenner et al., 2018).

The $\mu$-rhythm constitutes the dominant rhythm in the frequency spectrum of the sensorimotor cortex at rest (Hari, 2006; Haegens et al., 2011). The negative versus positive peaks of the $\mu$-rhythm in EEG represent states of high versus low excitability of corticospinal neurons as measured by MEP amplitude (Zrenner et al., 2018). Although corticospinal neurons and output neurons projecting to the M1 in the opposite hemisphere form segregate assemblies in different cortical layers (Jones and Wise, 1977), it is likely that their excitability states are linked, as indicated by common variation of conditioning MEP amplitude and SIHI (Ferbert et al., 1992; Ni et al., 2009; Ghosh et al., 2013).

Using the novel EEG-TMS technique (Zrenner et al., 2018), we tested here the effects of four different specific states of the conditioning and test M1 on effective interhemispheric connectivity expressed by SIHI: in phase for the high-excitability state (negative peak of the $\mu$-rhythm) or the low-excitability state (positive peak) or out of phase (conditioning M1 either at negative or positive peak and test M1 at the opposite phase). Consistent with the CTC theory, we hypothesized that the strongest SIHI will occur when the conditioning and test M1 are in phase for the high-excitability state; that is, when the two M1 communicate and input is maximal from the conditioning to test M1. Furthermore, we expected the weakest SIHI when the two M1 are out of phase with the conditioning M1 in the low-excitability state.

We consider this research as of high importance because demonstration of CTC at the systems level of the human brain will open the possibility to highly effectively modify brain connections by repetitive stimulation of the nodes of that connection at instants in time when they are phase synchronized.

\section{Materials and Methods}

Subjects. The study protocol was approved by the local ethics committee of the medical faculty of the University of Tübingen (protocol 716/ 2014BO2). The experiments conformed to the Declaration of Helsinki and were performed in accordance with the current TMS safety guidelines of the International Federation of Clinical Neurophysiology (Rossi et al., 2009). All subjects provided written informed consent before participation. Thirty healthy volunteers without a history of neurological or psychiatric disease or use of CNS active drugs, alcohol, or nicotine were screened. Sixteen subjects ( 9 female and 7 male; all right-handed according to the Edinburgh handedness inventory; mean age \pm 1 SD $29.0 \pm 9.5$ years; age range: $22-53$ years) fulfilled all of the following inclusion criteria (Zrenner et al., 2018): (1) resting motor threshold (RMT) of the right and left abductor pollicis brevis (APB) and/or right and left first dorsal interosseous (FDI) muscle $\leq 70 \%$ of maximum stimulator output (MSO); (2) stimulus intensity necessary to evoke MEP of $1 \mathrm{mV}$ in peakto-peak amplitude $\left(\mathrm{SI}_{1 \mathrm{mV}}\right) \leq 130 \%$ of RMT; (3) single peak in the $\mu$-band $(8-12 \mathrm{~Hz})>25 \%$ of total power in the current source density (CSD) power spectrum of the C3 and C4 EEG signals representing neural activity in the left and right sensorimotor cortices, respectively, with the subject at rest and eyes open; (4) at the stimulation intensities selected according to criteria 1 and 2 SIHI (percentage of conditioned over unconditioned MEP) $\leq 90 \%$. Threshold criteria 1 and 2 were selected to ensure that the TMS stimulator would be able to perform at the required intensities for the whole duration of the experiment. Criterion 3 ensured that the oscillation amplitudes were adequately large to enable our algorithm to estimate instantaneous phase of the trigger signal with sufficient accuracy (Hjorth, 1975; Zrenner et al., 2018). Twelve of 14 of the excluded subjects failed on the CSD power spectrum criterion and two of 14 subjects on the SIHI criterion.

Experimental setup. The present study was conducted based on a realtime, millisecond-resolution brain-state-dependent EEG-triggered TMS system that has been recently developed in our laboratory (Zrenner et al., 2018). This EEG-TMS setup uses an online output of the raw EEG signal and analyzes it in real time to trigger TMS pulses depending on the instantaneous oscillatory phase of the recorded EEG. For the experiments of the present study, the stimulation setup consisted of two passively cooled TMS double coils (PMD45-pCool, $45 \mathrm{~mm}$ winding diameter, MAG \& More) and two high-frequency magnetic stimulators (Research 100, MAG \& More) to deliver biphasic single cosine cycle pulses with a $160 \mu$ s period. The stimulator delivering the test stimulus (TS) was connected to a coil placed optimally over the hand representation area (the "hotspot," see below) of the right M1, with the handle of the coil pointing backward and $\sim 45$ degrees to the midsagittal line. The stimulator delivering the conditioning stimulus (CS) was connected to a coil placed similarly over the hand representation area of the left M1, but slight repositioning and reorienting of this coil was necessary in most of the subjects to fit both coils tangentially on the scalp (mean \pm 1 SD coil angle over left $\mathrm{M} 1$ relative to the central sulcus: $30.6^{\circ} \pm 16.5^{\circ}$ ). The chosen orientation of the coils ensured that the second phase of the biphasic pulse induced an electrical field in the brain from lateral-posterior to medial-anterior. This current orientation is effective in trans-synaptically activating corticospinal neurons and inducing corticocortical, interhemispheric interactions (Ferbert et al., 1992; Daskalakis et al., 2002). For both hemispheres, the motor hotspots were identified as the coil position and orientation resulting at a slightly suprathreshold stimulation intensity in maximum MEP amplitudes (Rossini et al., 2015). A vacuum pillow (Vacuform, B.u.W. Schmidt) and two fixation arms (Magic Arm, Lino Manfrotto) were used to immobilize the head and maintain fixed coil positions over the motor hotspots during the experiment. The magnetic stimulators were triggered through a transistor-transistor logic (TTL) trigger input from the real-time digital signal processing system. Stimulus intensities were set manually.

A stereoscopic neuronavigation system (Localite, RRID:SCR_016126) was used to register the subject's head to a standard Montreal Neurological Institute (MNI) brain anatomical dataset to record the coordinates of the motor hotspots and monitor throughout the experimental session the position of the two TMS coils in 3D space relative to the subject's head 

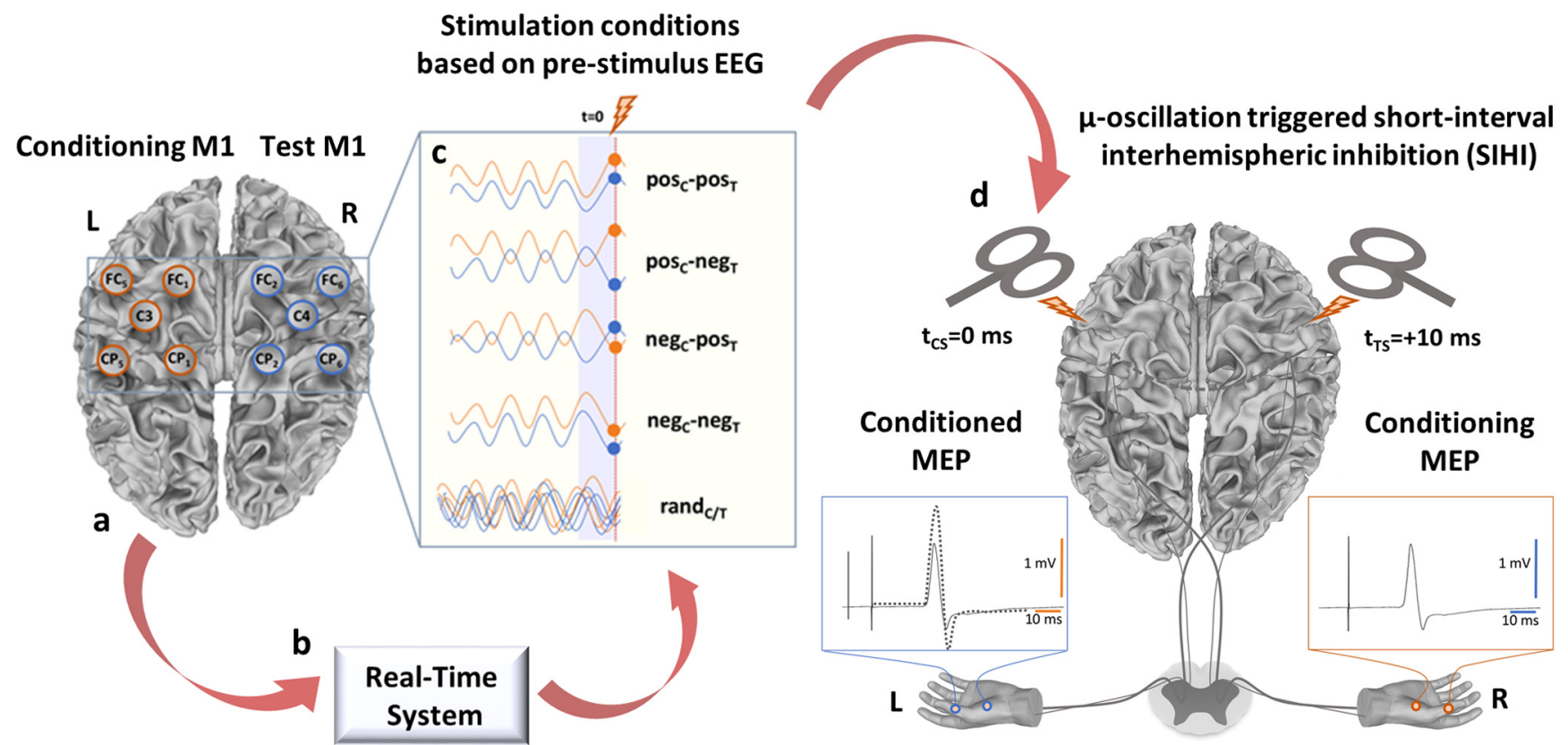

Figure 1. $\mu$-oscillation triggered SIHI. $\boldsymbol{a}, \boldsymbol{b}, \mathrm{Scalp}$ EEG raw data derived from 5-point sum-of-difference operators centered on the (3 and $(4 \mathrm{EEG}$ electrodes (Hjorth- $\mathrm{C} 3$ and Hjorth-C4) over the left and right sensorimotor cortices are streamed to a real-time system with 3 ms latency (a), where a processing algorithm is computed at a rate of $500 \mathrm{~Hz}$ (b). The EEG-data are $8-12 \mathrm{~Hz}$ band-pass filtered forward and backward, edge artifacts are removed, and coefficients for an autoregressive model are calculated from the filtered data. $\boldsymbol{c}, \boldsymbol{d}$, The signal is forward predicted (blue shaded area in $\boldsymbol{c}$ ), phase is estimated at time $0(t=0)$ using a Hilbert transform, and the two TMS stimulators $(\boldsymbol{d})$ are triggered at $0 \mathrm{~ms}$ (CS to the hand area left motor cortex) and $+10 \mathrm{~ms}$ or (in half of the subjects) $+12 \mathrm{~ms}$ (test stimulus TS to the hand area right motor cortex) when the preselected one of the five predefined phase conditions (c) is met in the Hjorth-C3 (orange) and Hjorth-C4 (blue) EEG signals. These correspond to the four possible combinations of positive (pos) and negative (neg) peaks of the ongoing sensorimotor $\mu$-rhythm in the conditioning (C) and the test (T) M1 (pos $-{ }^{-p_{0}} \mathrm{~S}_{\mathrm{T}}$, $\operatorname{pos}_{C}-$-neg $_{T}$ neg $_{C}-$ pos $_{T}$ neg $g_{C}-$ neg $_{T}$ ) and a random phase condition as control $\left(\right.$ rand $\left._{C T}\right)$. d, Short-interval interhemispheric inhibition is reflected by attenuation of the conditioned MEP (continuous line) compared with the nonconditioned test MEP (dotted line) recorded by surface EMG from the left-hand target muscles (only EMG electrodes on APB are shown; electrodes on first dorsal interosseus are not shown).

and to acquire the position of the coils at each TMS pulse. Manual adjustments of coil position were performed in case of coil displacement.

Scalp EEG was recorded from a 64-channel TMS compatible $\mathrm{Ag} / \mathrm{AgCl}$ sintered ring electrode cap (EasyCap) according to the 10-20 international system (Seeck et al., 2017). A 24-bit 80-channel biosignal amplifier was used for EEG recordings (NeurOne tesla with Analog Out Option, Bittium Biosignals). The data were acquired in DC mode with a headstage sampling rate of $80 \mathrm{kHz}$ for subsequent analysis. The analog output option of the amplifier was configured to recreate from the digital data a filtered and amplified parallel analog signal $(5 \mathrm{kHz}$ sampling rate per channel, $1.25 \mathrm{kHz}$ low-pass anti-aliasing filter) from a user-selectable subset of 16 amplifier channels covering left and right sensorimotor cortices. Out of this subset, 5-point "sum-of-difference" operators centered on $\mathrm{C} 3$ with surrounding electrodes FC1, FC5, CP1 and CP5 [(C3 $\mathrm{FC} 1)+(\mathrm{C} 3-\mathrm{FC} 5)+(\mathrm{C} 3-\mathrm{CP} 1)+(\mathrm{C} 3-\mathrm{CP} 5)$, referred to as Hjorth-C3] and C4 with surrounding electrodes FC2, FC6, CP2 and CP6 $[(\mathrm{C} 4-\mathrm{FC} 2)+(\mathrm{C} 4-\mathrm{FC} 6)+(\mathrm{C} 4-\mathrm{CP} 2)+(\mathrm{C} 4-\mathrm{CP} 6)$, referred to as Hjorth-C4] (Hjorth, 1975) were calculated by the real-time system at a rate of $500 \mathrm{~Hz}$ as orthogonal source derivations to isolate local sensorimotor $\mu$-oscillations from signal contamination by volume conduction and interference from other sources of alpha oscillations. The analog output stage consisted of a 16-bit digital-to-analog converter (DAC) system with a $10 \mathrm{kHz}$ frequency and a signal conditioning stage to produce a low-pass-filtered ( $500 \mathrm{~Hz}$ cutoff frequency, $24 \mathrm{~dB} /$ octave), scaled signal in the $\pm 5 \mathrm{~V}$ range, resolving sensor data at $0.1 \mu \mathrm{V}$. The analog-todigital conversion (ADC), digital filtering, DAC stage, and signal conditioning stage resulted in a constant latency of $3 \mathrm{~ms}$ between the signal at the EEG sensor and the signal at the analog output (Fig. 1).

MEPs were recorded by surface EMG using bipolar adhesive hydrogel electrodes (Kendall, Covidien) over the voluntarily relaxed left and right $\mathrm{APB}$ and FDI muscles in a belly-tendon montage ( $5 \mathrm{kHz}$ sampling rate, $0.16 \mathrm{~Hz}$ to $1.25 \mathrm{kHz}$ band-pass filter) and using the 24-bit 80-channel biosignal amplifier (NeurOne Tesla with Analog Out Option, Bittium Biosignals).
Real-time digital signal processing. Running in parallel to the widebandwidth 24-bit resolution $5 \mathrm{kHz}$ recording and archiving of the raw EEG data, a real-time data acquisition, digital processing, and magnetic stimulator control system was implemented as a Simulink Real-Time model (The MathWorks, R2016a, RRID:SCR_014744) executed on a dedicated xPC Target PC running the Simulink Real-Time operating system (DFI-ACP CL630-CRM mainboard). Details of the real-time digital signal processing have been described previously (Zrenner et al., 2018).

A multirate real-time model was programmed to process sliding windows of data at a fixed fundamental sample time step size of $0.5 \mathrm{~ms}$. The sliding window was configured to have a length of 1000 samples (500 $\mathrm{ms}$ ). The real-time system could be configured to trigger TMS pulses in a predetermined sequence or, in accordance with EEG power and phase of the acquired analog EEG signal, at either the EEG-positive or EEGnegative peak of the $\mu$-rhythm as determined by the spatially filtered C3 and C4 electrode EEG signals. The parameters and execution of the realtime system were asynchronously controlled from a standard PC running Microsoft Windows 8 and The MathWorks MATLAB R2016a through an Ethernet connection. The sequence and timing of TMS triggering were controlled from a separate room through a customized automatic script.

Real-time $\mu$-phase-dependent dual-site brain stimulation. The Hjorth$\mathrm{C} 3$ and Hjorth-C4 signals were used for estimation of power and phase. To estimate instantaneous phase at the edge of the sliding window ("time 0 "), an autoregressive forward prediction method for Hjorth-C3 and Hjorth-C4 signals was implemented (Chen et al., 2013). The sliding window was zero-phase forward and backward filtered using an FIR $8-12 \mathrm{~Hz}$ band-pass filter. The backward filtering step is part of a more general implementation that allows for use of IIR filters. When using FIR filters, it would be simpler to implement an equivalent phase detection algorithm more efficiently without the backward filtering step. Next, it was trimmed by $64 \mathrm{~ms}$ segments on both ends to reduce edge effects and the remaining $372 \mathrm{~ms}$ signal segment was used to generate the coefficients for 
a

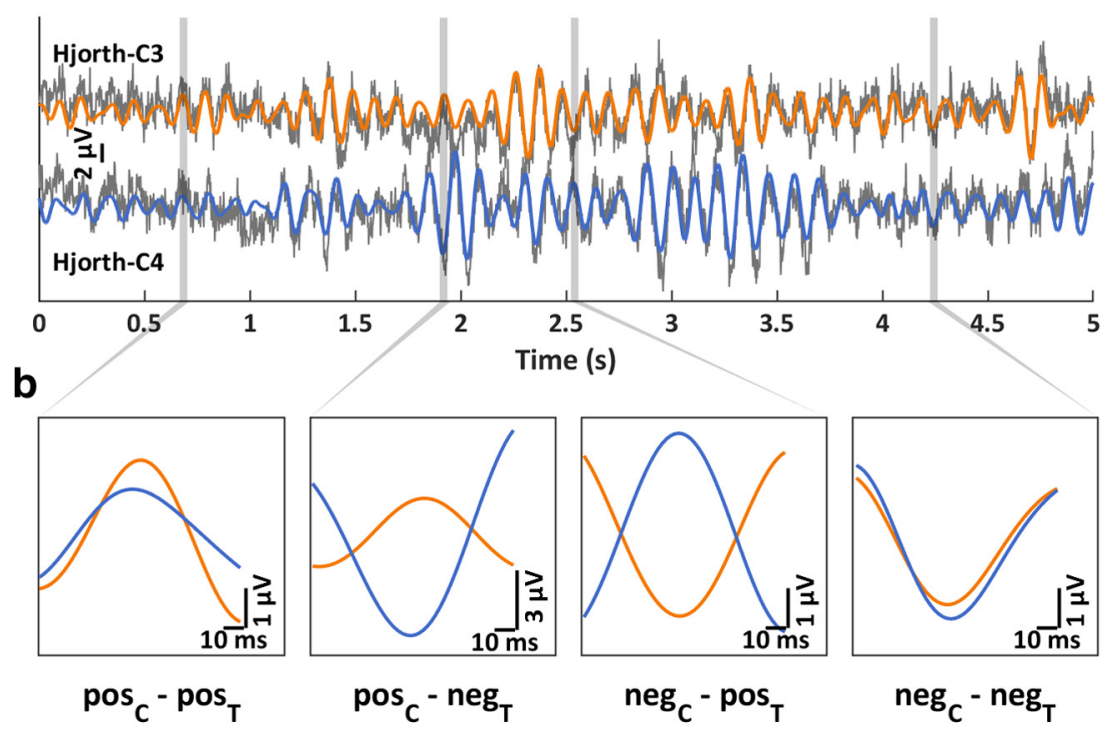

C

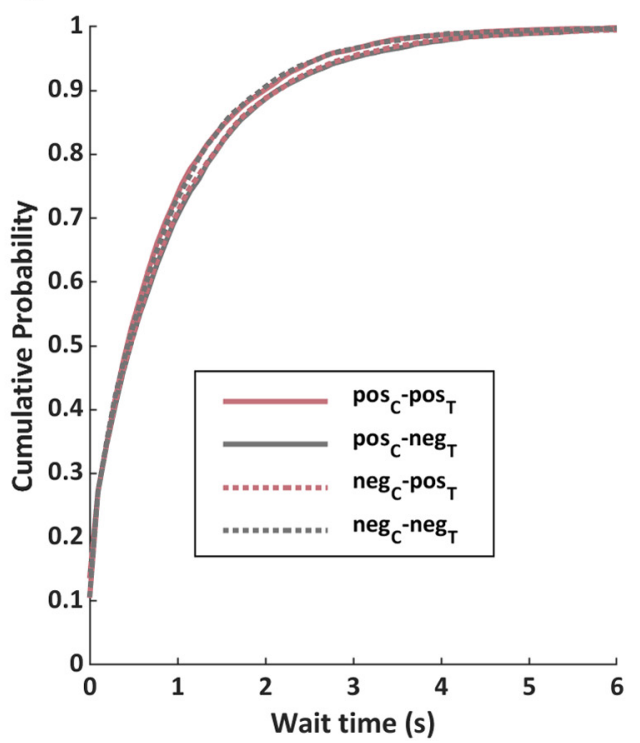

Figure 2. Frequency of occurrence of interhemispheric $\mu$-phase conditions in nonstimulated resting-state EEG. $\boldsymbol{a}$, Five seconds of scalp raw resting-state EEG recordings (gray traces, top: Hjorth-C3, bottom: Hjorth-C4) for one exemplary subject and corresponding $\mu$-band ( $8-12 \mathrm{~Hz}$ ) filtered signals (orange and blue traces, respectively). Vertical shaded gray bars highlight four events

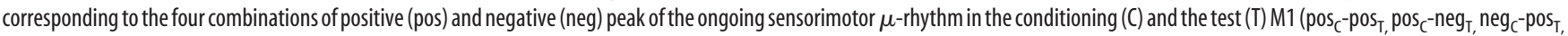
neg $_{C}$-neg $_{T}$ ) used for triggering of TMS pulses in the main experiment to determine effects of phase on short-interval interhemispheric inhibition. $\boldsymbol{b}$, Enlargement of the events highlighted by the vertical gray bars in $\boldsymbol{a}$. $\boldsymbol{c}$, Group average $(n=16)$ empirical cumulative probability distributions of waiting time between the occurrence of an event and the next occurrence of the same event for the 4 phase combinations in 5 min of spontaneous resting-state EEG.

an autoregressive forward prediction model (Yule-Walker, order 30), which served to iteratively compute a forecast $128 \mathrm{~ms}$ into the future \pm 64 ms around "time 0" (Zrenner et al., 2018). Instantaneous phase was estimated by calculating the analytic signal from the $128 \mathrm{~ms}$ window using a Hilbert transform. Simultaneously, the power spectra of the Hjorth-C3 and Hjorth-C4 signals were calculated from the entire sliding window using an autoregressive Yule-Walker model with order 200 to optimize spectral resolution in the $\mu$-frequency band ( $8-12 \mathrm{~Hz}$ ) (McFarland and Wolpaw, 2008). A TTL signal was generated to trigger the magnetic stimulator when the signal reached the target phase and a predetermined $\mu$-power threshold was exceeded. The $\mu$-power threshold was common for the Hjorth-C3 and Hjorth-C4 signals and ensured that the phase estimation was performed on physiological $\mu$-oscillation and not filtered noise. It was set manually at the beginning of the experiment and, if necessary, adjusted during the experiment to keep the intertrial interval between 2 and $4 \mathrm{~s}$. As we have reported previously (Zrenner et al., 2018), the phase prediction algorithm is highly accurate on average, but has an $\mathrm{SD}$ of $\sim 50^{\circ}$ over all trials. This variability is explained by the approach of forward-predicting a band-pass-filtered signal that requires a trade-off between the efficacy of the filter and the length of the prediction interval.

Experimental sessions. The experiment started with recording $5 \mathrm{~min}$ of resting-state EEG (eyes open, subjects instructed to relax and watch at a fixation cross at eye level $1 \mathrm{~m}$ in front of them) (Fig. 2).

Next, single-pulse TMS was delivered to the motor hotspots of the left and right $\mathrm{M} 1$ to determine $\mathrm{RMT}$ and $\mathrm{SI}_{1 \mathrm{mV}}$. RMT was determined to the nearest $1 \%$ of MSO and defined as the minimum intensity that elicited MEPs $\geq 50 \mu \mathrm{V}$ peak-to-peak amplitude in at least five of 10 consecutive trials (Groppa et al., 2012). SIHI from the left M1 to the right M1 was probed with a paired-pulse TMS paradigm with a suprathreshold CS delivered to the left M1, followed by a suprathreshold TS delivered to the right M1 at individualized delays of $10 \mathrm{~ms}$ ( $n=8$ subjects) or $12 \mathrm{~ms}$ ( $n=$ 8 subjects) (Ferbert et al., 1992) (Fig. 1d). These ISIs were chosen because they consistently lead to SIHI (Ferbert et al., 1992; Daskalakis et al., 2002). In the first six subjects, the ISI of $10 \mathrm{~ms}$ was tested first and, if not producing sufficient SIHI to meet the inclusion criterion (percentage of conditioned over unconditioned MEP $\leq 90 \%$ for at least one of the CS intensities, see below), the ISI of $12 \mathrm{~ms}$ was tested. In the following 10 subjects, the ISI of $12 \mathrm{~ms}$ was tested first and then $10 \mathrm{~ms}$ later if SIHI with ISI of $12 \mathrm{~ms}$ did not meet the inclusion criterion. CS was always applied over the left M1 because all subjects were right-handed and previous studies have shown that SIHI is stronger and more consistently expressed when conditioning the dominant left rather than the nondominant right M1 in right-handers (Netz et al., 1995; Kobayashi et al., 2003). In the SIHI measurements, one target muscle (either APB or FDI) was selected to define TS and CS intensities: the one with lower RMT in the right M1 or the FDI in case of equal RMTs (ABP: 5/16 subjects, FDI: 11/16 subjects). The intensity for the TS over the right M1 was adjusted to produce $\sim 1 \mathrm{mV}$ MEP peak-to-peak amplitude in the left-hand target muscle (when TS was given alone). To select the intensity of the CS, SIHI curves were obtained, where a CS of varying intensity (six different intensities, $90-140 \%$ of RMT, in steps of $10 \%$ RMT) preceded the TS. Ten conditioned MEPs were collected for each CS intensity, along with 10 unconditioned MEPs (i.e., TS was given alone) in randomized order. The peak-to-peak amplitudes of the conditioned MEPs were averaged for the different CS intensities and then expressed as a percentage of the mean unconditioned MEP amplitude. SIHI intensity curves were plotted (Fig. 3) and a CS intensity that corresponded to the steep, "nonsaturated" part of the SIHI curve was chosen for the main experiment. This procedure ensured for each subject that SIHI was approximately half-maximum and sensitive to assess possible effects of $\mu$-oscillation phase in the main experiment.

Thereafter, the main SIHI experiment with paired-pulse TMS was performed in four experimental blocks ( $\sim 250$ trials each) with fixed ISI, CS, and TS intensity. Within each block, five trigger conditions were tested, with equal numbers of paired pulses and unconditioned test pulses for either one of the following conditions. Trigger conditions (Fig. 1c) corresponded to the four possible combinations of positive (pos) and negative (neg) peaks of the ongoing sensorimotor $\mu$-rhythm in the conditioning $(\mathrm{C})$ left $\mathrm{M} 1$ and the test $(\mathrm{T})$ right $\mathrm{M1}$ : $\operatorname{pos}_{\mathrm{C}}-\operatorname{pos}_{\mathrm{T}}, \operatorname{pos}_{\mathrm{C}}-\mathrm{neg}_{\mathrm{T}}$ neg $_{\mathrm{C}}-\operatorname{pos}_{\mathrm{T}}$, neg $-\mathrm{geg}_{\mathrm{T}}$. A random phase condition $\left(\operatorname{rand}_{\mathrm{C} / \mathrm{T}}\right)$ served as control. The random phase trigger condition used the same $8-12 \mathrm{~Hz}$ power threshold criterion as the phase-triggered conditions, but, instead of requiring a positive or negative peak phase detection event to occur, the stimulators were automatically triggered after a uniformly random delay between 0 and $100 \mathrm{~ms}$. The five conditions were tested in random- 


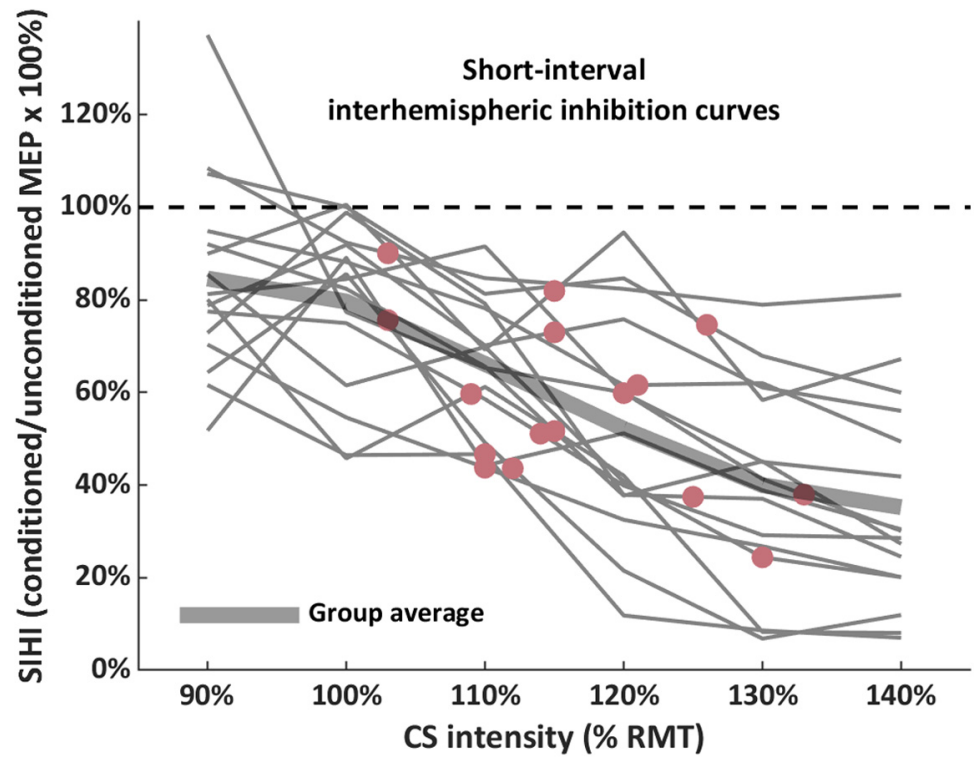

Figure 3. SIHI curves. The SIHI curves of the individual subjects are represented with thin gray lines. SIHI ( $y$-axis) is expressed as a percentage of the mean conditioned MEP over the mean unconditioned test MEP and plotted against CS intensity ( $x$-axis, in \%RMT). The (S preceded the test stimulus by $10 \mathrm{~ms}$ in $8 / 16$ subjects and by $12 \mathrm{~ms}$ in $8 / 16$ subjects. The red dots superimposed to the individual curves represent the CS intensity selected for the main experiment. For each subject, CS intensity was selected to induce on average $\sim 50 \%$ of maximum inhibition. The thick gray line represents the group mean SIHI curve of the studied sample.

ized order with a minimum intertrial interval of $2 \mathrm{~s}$ and a total of $\sim 200$ trials/condition. The mean intertrial interval $( \pm 1 \mathrm{SD})$ was $3.3 \pm 0.3 \mathrm{~s}$ and a one-way repeated measure ANOVA (rmANOVA) revealed no difference of mean intertrial intervals between the 4 specific phase conditions $\left(F_{(1.48,22.23)}=0.36, p=0.64, \eta_{\mathrm{p}}^{2}=0.02\right)$.

Data analysis. The $5 \mathrm{~min}$ of resting-state nonstimulated EEG were spatially filtered in each subject to obtain the Hjorth-C3 and Hjorth-C4 signals. Next, these signals were $\mu$-band $(8-12 \mathrm{~Hz})$ filtered and instantaneous phase was estimated taking the phase of the analytic signal obtained with a Hilbert transform. Events of interest $\left(\operatorname{pos}_{C^{-}} \operatorname{pos}_{T}\right.$, $\operatorname{pos}_{C^{-}}$ neg $_{\mathrm{T}}$ neg $_{\mathrm{C}}-$-pos $_{\mathrm{T}}$, neg $\mathrm{g}_{\mathrm{C}}-\mathrm{neg}_{\mathrm{T}}$ ) were marked (with a phase tolerance of $\pm 1 / 4$ $\pi)$. The waiting time for a particular event was then analyzed as the occurrence of this event and the next occurrence of the same event for each of the 4 events of interest in the 5 min of resting-state EEG. A rmANOVA revealed that there was no difference between events of interest for the waiting time at $50 \%$ cumulative probability $\left(F_{(1.07,16.11)}=\right.$ $0.54, p=0.49 ; \eta_{\mathrm{p}}^{2}=0.04 ; \operatorname{pos}_{\mathrm{C}}-\operatorname{pos}_{\mathrm{T}}: 0.43 \pm 0.14 \mathrm{~s}, \operatorname{pos}_{\mathrm{C}}-$ neg $_{\mathrm{T}}: 0.48 \pm$ $0.17 \mathrm{~s}, \operatorname{neg}_{\mathrm{C}}-\operatorname{pos}_{\mathrm{T}}: 0.47 \pm 0.14 \mathrm{~s}$, neg $_{\mathrm{C}}-$ neg $_{\mathrm{T}}: 0.44 \pm 0.13 \mathrm{~s}$ ) (Fig. $2 c$ ). Another rmANOVA demonstrated that also the likelihood of occurrence was not different between the 4 events of interest $\left(F_{(1.01,15.15)}=0.91, p=\right.$ $0.36, \eta_{\mathrm{p}}^{2}=0.06 ; \operatorname{pos}_{\mathrm{C}^{-}} \operatorname{pos}_{\mathrm{T}}: 26.2 \pm 4.5 \%, \operatorname{pos}_{\mathrm{C}^{-}} \mathrm{neg}_{\mathrm{T}}: 23.9 \pm 4.5 \%$, neg $_{\mathrm{C}^{-}}$ $\operatorname{pos}_{\mathrm{T}}: 24.0 \pm 4.3 \%$, neg ${ }_{\mathrm{C}}-$ neg $\left._{\mathrm{T}}: 26.0 \pm 4.3 \%\right)$.

EMG and EEG data processing for the main experiment was performed using the Fieldtrip open source toolbox (Oostenveld et al., 2011) and customized analysis scripts on MATLAB (The MathWorks, R2016a, RRID:SCR_001622). EMG signals were zero-phase band-pass filtered $(20-500 \mathrm{~Hz})$ with a third-order Butterworth filter and an additional third order zero-phase Butterworth notch filter $(49-51 \mathrm{~Hz})$ to reduce power line noise. Trials contaminated by involuntary muscle contraction in the $500 \mathrm{~ms}$ period before the TMS pulse were discarded (mean \pm 1 SD: $5.2 \pm 2.2 \%$ of all trials) because preinnervation increases MEP amplitude (Hallett, 2007). Single-trial peak-to-peak MEP amplitudes were automatically determined in the remaining trials within $20-45 \mathrm{~ms}$ after the TMS pulse.

For the EEG analysis, the continuous EEG signal was first segmented into epochs from 500 to $1 \mathrm{~ms}$ before the CS marker (prestimulation period). Next, manual artifact rejection was performed. Epochs with artifacts in one or more channels were discarded (mean \pm 1 SD: $6.5 \pm$ $4.2 \%$ of all epochs). Single channels with artifact contamination in the majority of epochs were removed (mean \pm 1 SD: $4 \pm 2$ ). Independent component analysis (ICA) based on a FastICA decomposition algorithm with a symmetric approach and the "Gauss" contrast function for finding the weight of matrix was applied (Hyvärinen et al., 2010). The resulting ICA components were visually inspected for topography, single-trial time course, average time course, and power spectrum. Components representing eye blinking, eye movements, and heartbeat were removed. After ICA cleaning, removed channels were spline interpolated using the signals of the neighboring channels (Perrin et al., 1989). EEG signals were then rereferenced to an average reference montage. Analysis of the origin of the Hjorth-C3 and Hjorth-C4 signals was provided in CSD topographical plots (Fig. 4). This corroborated that the positive and negative peaks of the EEG signal used for TMS triggering were specifically localized over the left and right hemispheric sensorimotor cortices.

After the experiment, the resting-state EEG data were fed into the real-time system and triggers for the five trigger conditions were set in the data. These nonstimulated trials were used to determine the actual phase on the Hjorth-C3 signal at the time of the CS trigger and on the Hjorth-C4 signal at the time of the TS trigger and thus to assess the accuracy of the real-time system (rose plots in Fig. 4). Experimental design and statistical analysis. Statistical analyses were performed with IBM SPSS Statistics version 23 (RRID:SCR_002865). Distribution of data was checked with the Shapiro-Wilk test. All data were normally distributed $(p>0.05)$ and therefore analyzed with parametric tests. SIHI was defined as the percentage of the mean conditioned MEP amplitude over mean unconditioned MEP amplitude (SIHI = conditioned MEP/unconditioned MEP $\times 100 \%$ ); that is, smaller SIHI values represent stronger inhibition. The effects of $\mu$-oscillation phase conditions on test MEP amplitude, conditioning MEP amplitude, and SIHI were tested using two-way rmANOVA with the within-subject effects of PHASE (5 levels: $\operatorname{pos}_{\mathrm{C}}-$ pos $_{\mathrm{T}}, \operatorname{pos}_{\mathrm{C}}-$ neg $_{\mathrm{T}}$, neg $_{\mathrm{C}}-\operatorname{pos}_{\mathrm{T}}$, neg $_{\mathrm{C}}-\mathrm{neg}_{\mathrm{T}}, \operatorname{rand}_{\mathrm{C} / \mathrm{T}}$ ) and MUSCLE (2 levels: APB, FDI). To disentangle effects of phase synchronicity (SYNC) from effects of local excitability in the conditioning left $\mathrm{M} 1$ and test right M1, another rmANOVA with the within-subject effects of SYNC (two levels: in phase $\left(\right.$ neg $_{\mathrm{C}}-\mathrm{neg}_{\mathrm{T}}, \operatorname{pos}_{\mathrm{C}}-$ pos $_{\mathrm{T}}$ ) versus out of phase (neg ${ }_{\mathrm{C}}-\operatorname{pos}_{\mathrm{T}}, \operatorname{pos}_{\mathrm{C}}-\mathrm{neg}_{\mathrm{T}}$ ), PHASE in test M1 (two levels: negative peak versus positive peak) and MUSCLE (two levels: APB, FDI) was performed. The SYNC $\times$ PHASE in test M1 interaction represents the effect of PHASE in the conditioning M1. Mauchly's test examined sphericity and, in case of violation of sphericity, the Greenhouse-Geisser correction of degrees of freedom was applied. Post hoc paired two-tailed $t$ tests were applied whenever main effects or their interactions were significant. The significance level for all statistical tests was set to $p<$ 0.05 . Data are given as means \pm 1 SEM unless indicated otherwise.

\section{Results}

All procedures were well tolerated and no adverse events were noted. TMS measures are presented as means \pm 1 SEM.

The CSD plots of the EEG signal in the 20 ms preceding the trigger showed a highly localized positivity/negativity over the left and right $\mathrm{M} 1$ regions in all phase-specific trigger conditions, with almost no contamination by occipital alpha (Fig. 4). This suggested that the Hjorth-C3 and Hjorth-C4 EEG signal that was used for triggering the TMS pulses originated predominantly from the stimulated primary sensorimotor cortices.

The full design for testing SIHI is illustrated in Figure 1. It involved five PHASE conditions (Fig. 1c) and single-pulse TMS of the test M1 (right M1) and recording of associated muscle 

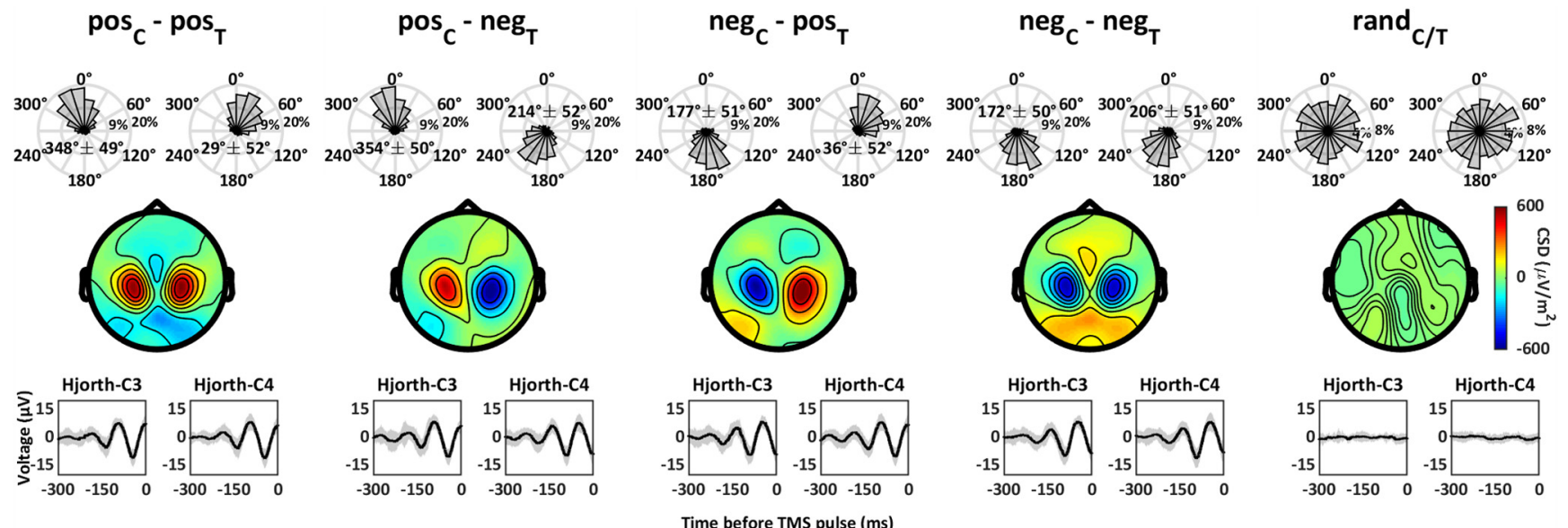

Figure 4. SIHI triggered on the instantaneous phase of sensorimotor $\mu$-oscillation over left and right motor cortex. Top, Distribution of estimated phase angle at the time of the CS trigger for the conditioning motor cortex (left M1, left in each pair of rose plots) and TS trigger (10 or 12 ms later) for the test motor cortex (right M1, right) in triggered nonstimulated resting-state trials in the five different phase trigger conditions, indicated in the headers. Phase angles are binned (width, $18^{\circ}$ ) and frequencies are indicated (inner ring $=9 \%$, outer ring $=20 \%$ for all phase-specific conditions, inner ring $=4 \%$, outer ring $=8 \%$ for the random phase condition). Angular means $\pm 1 S D$ are indicated in the phase distribution plots for all phase-specific conditions. Middle, Group mean CSD plots in the $20 \mathrm{~ms}$ preceding TMS. Amplitudes (in $\mu \mathrm{V} / \mathrm{m}^{2}$ ) are indicated by the color bar. Bottom, Grand averages across all subjects and trials of raw sensorimotor Hjorth-C 3 and Hjorth-C $4 \mathrm{EEG}$ signals preceding the TMS pulse at $0 \mathrm{~ms}$. Shadings represent \pm 1 SD physiological shifts in $\mu$-oscillation frequency across different trials and individuals are responsible for the declining oscillation amplitudes with distance to the TMS pulse.

responses (MEP), providing a reference measure (Fig. 1d, left hand: unconditioned MEP = dashed line) for comparison with dual-coil, paired-pulse TMS, where a conditioning TMS pulse of the conditioning M1 (left M1) precedes the right M1 test pulse by $10-12 \mathrm{~ms}$ (Fig. $1 d$, left hand: conditioned MEP = solid line). Importantly, the conditioning pulse was also suprathreshold, evoking MEPs (Fig. $1 d$, right hand: conditioning MEP = solid line). SIHI was expressed as the ratio of conditioned over unconditioned MEP amplitude in the left hand. The three measures (unconditioned MEP, conditioning MEP, and SIHI) allowed to infer to what extent SIHI, the measure of effective interhemispheric connectivity, covaried with interhemispheric PHASE relations and PHASE-dependent variation of local excitability in the conditioning and test M1. The following sections report the findings on these three measures.

\section{Effect of phase of $\mu$-rhythm on unconditioned test MEP amplitude}

rmANOVA showed a significant effect of PHASE $\left(F_{(4,60)}=12.53\right.$, $\left.p<0.001, \eta_{\mathrm{p}}^{2}=0.46\right)$, but no effects of $\operatorname{MUSCLE}\left(F_{(1,15)}=0.52\right.$, $\left.p=0.48, \eta_{\mathrm{p}}^{2}=0.03\right)$ or the PHASE $\times$ MUSCLE interaction $\left(F_{(1.79,26.80)}=0.54, p=0.71, \eta_{\mathrm{p}}^{2}=0.04\right)$. The mean unconditioned test MEP amplitudes ( \pm 1 SEM) pooled across the two target muscles were as follows: $\operatorname{pos}_{\mathrm{C}^{-}} \operatorname{pos}_{\mathrm{T}}: 1.20 \pm 0.11 \mathrm{mV}, \operatorname{pos}_{\mathrm{C}^{-}}$ neg $_{\mathrm{T}}: 1.37 \pm 0.12 \mathrm{mV}$, neg $_{\mathrm{C}}-\operatorname{pos}_{\mathrm{T}}: 1.18 \pm 0.10 \mathrm{mV}$, neg $_{\mathrm{C}}-$ neg $_{\mathrm{T}}$ : $1.45 \pm 0.14 \mathrm{mV}$, rand $_{\mathrm{C} / \mathrm{T}}: 1.32 \pm 0.12 \mathrm{mV}$ (Fig. 5). Post hoc twotailed paired $t$ tests showed several significant pairwise differences as indicated in Figure 5.

The data replicate previous findings (Zrenner et al., 2018) by showing that MEPs are larger when the test M1 is stimulated at the negative peak of the $\mu$-rhythm compared with the positive b

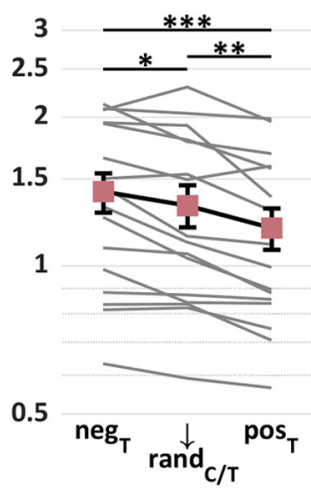

Figure 5. Effect of phase of $\mu$-rhythm on unconditioned test MEP amplitude. $\boldsymbol{a}$, Mean $(n=16) \pm 1$ SEM unconditioned test (titudes (y-axis, mean MEP amplitudes in $\mathrm{mV}$ ) evoked by the test stimulus alone applied to right test $\mathrm{M} 1$ in the 5 different -axis). Data have been merged according to the phase in test M1. MEP amplitude is larger at the negative peak versus positive peak condition in all subjects, with intermediate MEP amplitudes in the random phase condition in $12 / 16$ subjects. ${ }^{*} p<$ $0.05,{ }^{* *} p<0.01,{ }^{* * *} p<0.001$.

peak, with intermediate MEP amplitudes in the random phase condition.

Effect of phase of $\boldsymbol{\mu}$-rhythm on conditioning MEP amplitude rmANOVA showed a significant effect of PHASE $\left(F_{(4,60)}=4.10\right.$, $\left.p=0.005, \eta_{\mathrm{p}}^{2}=0.22\right)$, but no effect of $\operatorname{MUSCLE}\left(F_{(1,15)}=0.66\right.$, $\left.p=0.43, \eta_{\mathrm{p}}^{2}=0.04\right)$ or the PHASE $\times$ MUSCLE interaction $\left(F_{(2.66,39.93)}=0.49, p=0.67, \eta_{\mathrm{p}}^{2}=0.03\right)$.

Mean conditioning MEP amplitudes ( \pm 1 SEM) pooled across the two target muscles were as follows: $\operatorname{pos}_{\mathrm{C}}-\operatorname{pos}_{\mathrm{T}}$ : $0.93 \pm 0.12$ $\mathrm{mV}, \operatorname{pos}_{\mathrm{C}}-$ neg $_{\mathrm{T}}: 0.94 \pm 0.13 \mathrm{mV}$, neg $_{\mathrm{C}}-\operatorname{pos}_{\mathrm{T}}: 1.05 \pm 0.13 \mathrm{mV}$, neg $_{\mathrm{C}}$-neg $_{\mathrm{T}}: 0.99 \pm 0.12 \mathrm{mV}$, $\operatorname{rand}_{\mathrm{C} / \mathrm{T}}: 1.01 \pm 0.13 \mathrm{mV}$ (Fig. 6). Post hoc two-tailed paired $t$ tests showed several significant pairwise differences as indicated in Figure 6. In particular, the neg $\mathrm{C}^{-}$ $\operatorname{pos}_{\mathrm{T}}$ condition, that is, when the conditioning left M1 is stimulated at the negative peak of the $\mu$-rhythm, revealed larger MEPs than most of the other conditions. The weaker effect of 
a

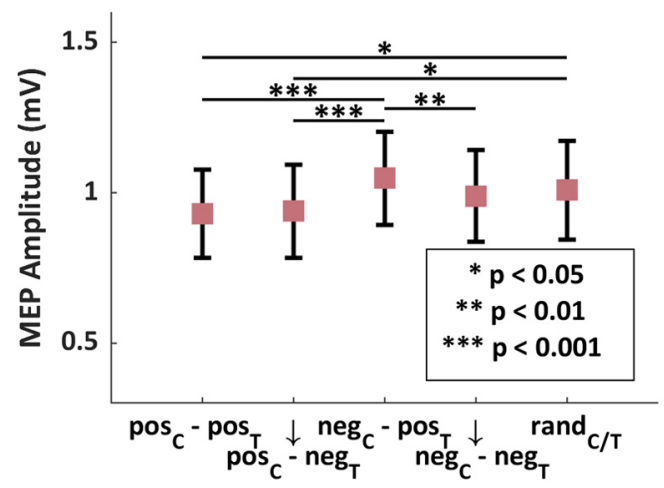

b

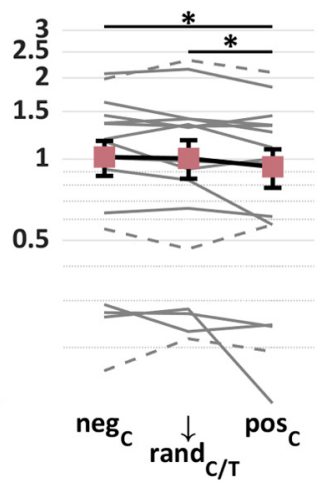

Figure 6. Effect of phase of $\mu$-rhythm on conditioning MEP amplitude. $\boldsymbol{a}$, Mean $(n=16) \pm 1$ SEM unconditioned test MEP amplitudes ( $y$-axis, mean MEP amplitudes in $\mathrm{mV}$ ) evoked by the conditioning stimulus applied to left $\mathrm{M} 1$ in the 5 different phase conditions ( $x$-axis). Data are pooled over the two target muscles (APB, FDI). $\boldsymbol{b}$, Individual MEP data (in millivolts, logarithmic scale, $y$-axis). Data have been merged according to the phase in conditioning M1. MEP amplitude is larger at the negative peak versus positive peak condition in $13 / 16$ subjects. ${ }^{*} p<0.05,{ }^{* *} p<0.01,{ }^{* * *} p<0.001$.

a

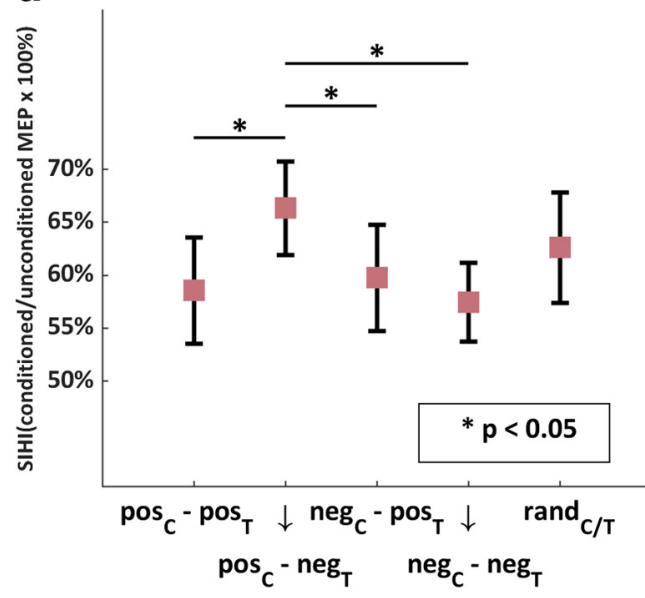

b

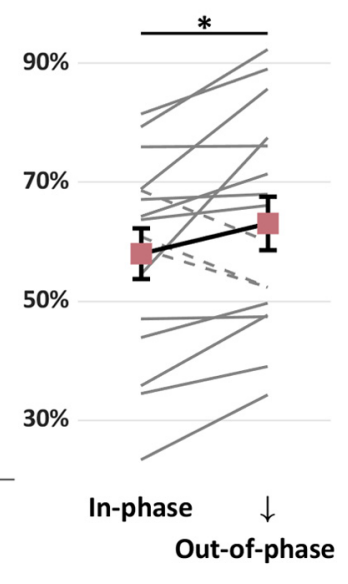

Figure 7. Effect of phase of $\mu$-rhythm on SIHI. $\boldsymbol{a}$, Mean $(n=16) \pm 1$ SEM SIHI ( $y$-axis) expressed as a percentage of the mean conditioned MEP over the mean unconditioned test MEP and is shown for the five phase conditions ( $y$-axis). Data are pooled over the two target muscles (APB, FDI). $\boldsymbol{b}$, Individual SIHI data (as a percentage, $y$-axis). Data have been merged for in-phase $\left(\operatorname{pos}_{C}-\operatorname{pos}_{T}\right.$,

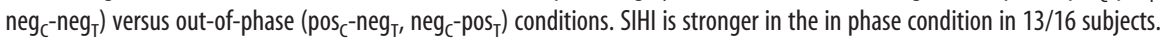
${ }^{*} p<0.05$.

PHASE on conditioning MEP amplitude compared with test MEP amplitude may have been caused by the necessary adjustments of location and rotation of the conditioning stimulating coil (see Materials and Methods) because previous data showed this to be critical for the effect size of the PHASE effect (see Fig. 5 in Zrenner et al., 2018).

\section{Effect of phase of $\boldsymbol{\mu}$-rhythm on SIHI}

rmANOVA showed a strong effect of $\operatorname{PHASE}\left(F_{(4,60)}=3.02\right.$, $\left.p=0.024, \eta_{\mathrm{p}}^{2}=0.17\right)$, but no effect of $\operatorname{MUSCLE}\left(F_{(1,15)}=0.26\right.$, $\left.p=0.62, \eta_{\mathrm{p}}^{2}=0.02\right)$ or PHASE $\times$ MUSCLE interaction $\left(F_{(4,60)}=\right.$ $\left.0.80, p=0.53, \eta_{\mathrm{p}}^{2}=0.05\right)$ on SIHI.

Mean SIHI ( \pm 1 SEM) pooled across the two target muscles was as follows: $\operatorname{pos}_{\mathrm{C}}-\operatorname{pos}_{\mathrm{T}}: 59 \pm 5 \%, \operatorname{pos}_{\mathrm{C}^{-}}$neg $_{\mathrm{T}}: 66 \pm 4 \%$ neg $_{\mathrm{C}^{-}}$ $\operatorname{pos}_{\mathrm{T}}: 60 \pm 5 \%$ neg $_{\mathrm{C}}-$ neg $_{\mathrm{T}}: 57 \pm 4 \%$, rand $_{\mathrm{C} / \mathrm{T}}: 63 \pm 5 \%$ (Fig. 7 ). Post hoc two-tailed paired $t$ tests showed significant pairwise differences as indicated in Figure 7.

These data suggest a relevant role of local excitability in the conditioning and test $\mathrm{M} 1$, resulting in least SIHI in the $\operatorname{pos}_{\mathrm{C}^{-}}$

neg $_{\mathrm{T}}$, that is, when conditioning MEP amplitude is small (cf. Fig. 6) and unconditioned test MEP amplitude is large (cf. Fig. 5).

Previous studies have shown that SIHI increases with increasing conditioning MEP amplitude (Ferbert et al., 1992; Ni et al., 2009; Ghosh et al., 2013), but decreases with increasing test MEP amplitude (Ferbert et al., 1992; Daskalakis et al., 2002).

To disentangle the role of phase synchrony (SYNC) from effects of local PHASE in the conditioning and test M1, we performed a rmANOVA with the within-subject effects of SYNC (two levels: in phase vs out of phase), PHASE in the test M1 (two levels: negative peak vs positive peak), and MUSCLE (two levels: APB, FDI). The SYNC $\times$ PHASE in the test $\mathrm{M} 1$ interaction represents the effect of PHASE in the conditioning M1.

The rmANOVA showed significant effects of SYNC $\left(F_{(1,15)}=5.16, p=0.038\right.$, $\left.\eta_{\mathrm{p}}^{2}=0.26\right)$ and PHASE in the conditioning $\mathrm{M} 1\left(F_{(1,15)}=5.41, p=0.034, \eta_{\mathrm{p}}^{2}=\right.$ $0.27)$, but no effect of PHASE in the test $\operatorname{M1~}\left(F_{(1,15)}=1.47, p=0.25, \eta_{\mathrm{p}}^{2}=0.09\right)$, $\operatorname{MUSCLE}\left(F_{(1,15)}=0.29, p=0.60, \eta_{\mathrm{p}}^{2}=\right.$ $0.02)$ or interactions of MUSCLE with any of the other effects (all $p>0.2$, all $\eta_{\mathrm{p}}^{2}$ $<0.1)$. Stronger effective connectivity (i.e., smaller values of SIHI) occurred in the in phase compared with out of phase conditions and in the conditioning M1 high-excitability state (i.e., negative peak of the $\mu$-rhythm in the conditioning M1) (Fig. 7).

To rule out that the duration of the synchronized state before the TMS pulse has contributed to the observed SIHI effects, we estimated the phase-locking value (PLV) over the $500 \mathrm{~ms}$ preceding TMS (Lachaux et al., 1999). We used the Hilbert transform preceded by singular spectrum decomposition (SSD) of the signal, as described previously (Lowet et al., 2016). The SSD component representing the $\mu$-rhythm was automatically identified by estimating the power spectrum of each resulting component and selecting the component with the largest peak in the $5-15 \mathrm{~Hz}$ frequency band. This approach isolated the $\mu$-oscillation minimizing the loss of signal at the edges due to bandpass filtering and Hilbert transform. The resulting PLV between the Hjorth-C3 and Hjorth-C4 signals in the $\mu$-phasetriggered conditions is reported in Figure 8. The PLV time course is virtually identical across conditions, ruling out the possibility that there were different durations of the pre-TMS synchronization between the Hjorth-C3 and Hjorth-C4 signals between the different PHASE conditions.

\section{Discussion}

The extent to which interhemispheric communication can be predicted by phase relations of ongoing oscillations in the human sensorimotor cortex is thus far unknown because electrophysio- 


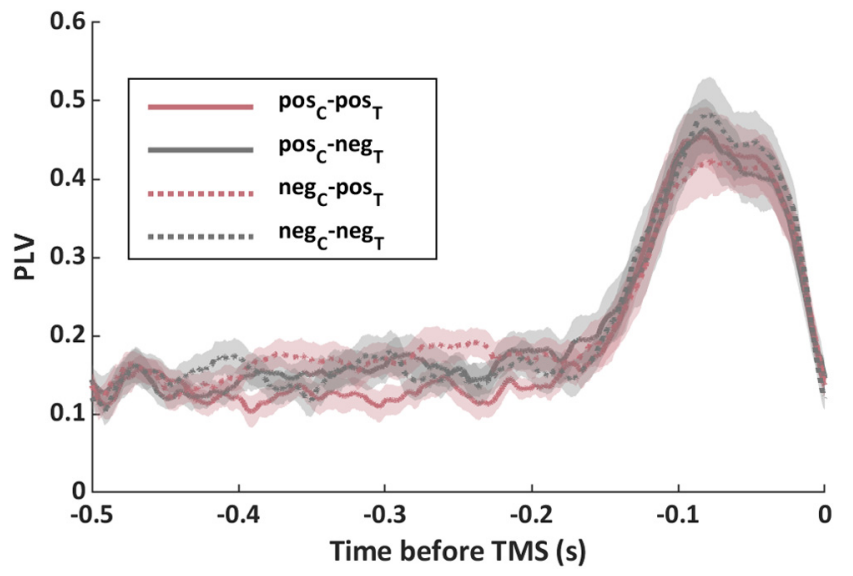

Figure 8. Time course of the PLV between the Hjorth-C 3 and Hjorth-C 4 signals before TMS for the $4 \mu$-phase trigger conditions (group average \pm 1 SEM, $n=16$ ). The PLV shows a very similar pattern across conditions, ruling out the possibility that different durations of the preTMS synchronization between the trigger signals across the different $\mu$-phase conditions may have played a role in the obtained SIHI results. For the time points close to TMS (up to $\sim-40$ $\mathrm{ms}), \mathrm{PLV}$ estimation is distorted by the edge effect of the Hilbert transform used to estimate the phase of the $\mu$-oscillation.

logical studies investigating interhemispheric sensorimotor interactions have disregarded the continuously fluctuating brain dynamics. We report here first findings in healthy human subjects in whom SIHI, a marker of effective inhibitory interhemispheric motor connectivity, was investigated with dual-site millisecond-resolved brain-state-dependent EEG-triggered TMS based on the instantaneous phase of the sensorimotor $\mu$-rhythm in the two hemispheres. Instantaneous phase relation of the Hjorth-C3 and Hjorth-C4 signals from the sensorimotor cortices of the two hemispheres continuously fluctuates between in phase and out of phase conditions (Fig. 2), similar to incessantly varying phase correlations in bihemispheric M1 local field potential recordings (Murthy and Fetz, 1996).

Consistent with previous open-loop paired-coil TMS studies that demonstrated an increase of SIHI with increasing conditioning MEP amplitude (Ferbert et al., 1992; Ni et al., 2009; Ghosh et al., 2013), our findings show effects of local excitability in the conditioning M1; that is, stronger SIHI when the conditioning M1 is stimulated in the high-excitability state (negative peak of the $\mu$-rhythm) (Fig. 7). Importantly, our findings also demonstrate for the first time a significant effect of interhemispheric $\mu$-phase synchronicity, with stronger SIHI in the in phase than out of phase conditions (Fig. 7). These findings are predicted by the CTC theory (Fries, 2005, 2015) and experimental evidence from multiunit recordings in cat and monkey visual cortex (Womelsdorf et al., 2007).

Negative deflections in the surface EEG reflect synchronized EPSCs at the apical dendrites of radially oriented pyramidal cells (Buzsáki et al., 2012). TMS is thought to activate motor output neurons in M1 predominantly transsynaptically by excitation of long-range corticocortical axons at the precentral and postcentral gyrus crowns where the TMS-induced electrical fields are maximal (Laakso et al., 2014; Bungert et al., 2017; Laakso et al., 2018). Accordingly, excitation through the TMS pulse given at the time of the negative peak of the sensorimotor $\mu$-rhythm will add to the elevated firing rate of neurons in premotor and somatosensory cortex that are projecting to M1 (Haegens et al., 2011) and this will lead to recruitment of a larger fraction of corticospinal neurons in M1, as indexed by the larger MEP amplitude (Figs. 5, 6)
(Zrenner et al., 2018). Long-range corticocortical axons from somatosensory cortex terminate in monkey Brodmann area 4 (primary motor cortex) in cortical layers V and III (DeFelipe et al., 1986), where the corticospinal cells and transcallosal projection cells to the opposite M1 are located, respectively (Jones and Wise, 1977). Therefore, it is likely that the excitability states of corticospinal cells and transcallosal projection cells are comodulated as a function of $\mu$-rhythm phase. Furthermore, previous SIHI experiments demonstrated that conditioning MEP amplitude and SIHI are directly related (Ni et al., 2009; Ghosh et al., 2013). SIHI is very likely mediated through motor callosal fibers connecting the hand areas of the two M1 because there is a direct correlation of SIHI magnitude with microstructural integrity of these fibers as measured by diffusion tensor imaging (Wahl et al., 2007). The transcallosal connection is excitatory (glutamatergic) and inhibition is mediated by termination of this connection on inhibitory interneurons in the opposite M1 (Innocenti, 1986). These interneurons receive long-range excitatory input from other sources such as somatosensory cortex (Markram et al., 2004). This anatomical circuitry predicts that, at the negative peak of the $\mu$-rhythm, the SIHI-mediating inhibitory interneurons in the test M1 will be in a state of high sensitivity to excitatory synaptic input (e.g., from the transcallosal projection neurons) because they are then depolarized by the elevated input from somatosensory cortex. Together with maximal spike output of transcallosal projection neurons in the conditioning M1, this would explain why maximal SIHI was obtained when both M1 were phase synchronized at the negative peak of the $\mu$-rhythm, as predicted by the CTC theory.

The present findings are also consistent with noninvasive brain stimulation experiments that investigated the consequences on SIHI after altering corticospinal excitability. OneHertz repetitive TMS over the conditioning M1 resulted in increased corticospinal excitability of the nonstimulated test M1 and/or decreased excitability of the conditioning M1, in parallel with a decrease in SIHI (Gilio et al., 2003; Pal et al., 2005). Similarly, transcranial direct current stimulation of bilateral M1 resulted in deceased corticospinal excitability under the cathode, increased excitability under the anode, and decreased SIHI from the less excitable M1 to the more excitable M1 and, vice versa, increased SIHI when testing from the more to less excitable M1 (Tazoe et al., 2014).

Furthermore, this conceptual background also explains why we found weakest SIHI when the conditioning M1 was in the low-excitability state at the positive peak of the $\mu$-rhythm and out of phase with the test M1 in the high-excitability state. The reverse out-of-phase condition (conditioning M1 in high-excitable state, test M1 in low-excitable state) resulted in stronger SIHI (Fig. 7).

Finally, our findings have a potentially important translational perspective. We showed previously that single-site repetitive burst stimulation at the high-excitability state of the sensorimotor cortex resulted in long-term potentiation-like increase in corticospinal excitability, but not when applying the same repetitive stimulation at the low-excitability state (Zrenner et al., 2018). It might be expected that, in conjunction with the CTC theory and the principle of cooperativity for induction of synaptic plasticity (Sjöström et al., 2001), dual-site repetitive TMS of the two M1 at instances of phase synchrony for the highexcitability state will be most successful in modifying interhemispheric effective connectivity as expressed by SIHI than any of the other states that have been tested in the present experiments. $\mathrm{SIHI}$ from contralesional to ipsilesional M1 is exaggerated in the 
early phase after stroke (Boddington and Reynolds, 2017) and current approaches of therapeutic brain stimulation are targeting this abnormality by downregulating corticospinal excitability in the contralesional M1 with moderate effect size (Grefkes et al., 2010; Avenanti et al., 2012).

This study has several limitations. First, we cannot be certain that the fluctuating synchronization of the $\mu$-rhythm in the sensorimotor cortices of the two hemispheres is mediated through the corpus callosum. Although oscillatory synchrony across hemispheres is considered predominantly mediated by transcallosal connections in visual cortex (Engel et al., 1991), a significant contribution of a common modulatory drive from subcortical regions such as the thalamus cannot be excluded (Vijayan and Kopell, 2012). However, this is not critical for the interpretation of the present findings because there is strong evidence that SIHI, the outcome measure of this study, is largely, if not exclusively, mediated through motor callosal fibers (see above). Second, it is not certain that the EEG oscillations that were used for TMS triggering were generated by the sensorimotor $\mu$-rhythm and not by another sensorimotor rhythmic activity in the alphafrequency band that shows increased interhemispheric coherence during voluntary unilateral index finger movements (Florian et al., 1998). However, we have confirmed during screening that the Hjorth-3 and Hjorth-C4 sensorimotor oscillations in the alphafrequency range desynchronized in all subjects with fist clenching, an accepted criterion for $\mu$-rhythm identification (Chatrian et al., 1959; Salenius et al., 1997). Furthermore, there was no relevant contribution from the occipital alpha-rhythm, as can be noted from the focal CSD potentials over the sensorimotor cortices and absence of dipoles over the occipital cortex (Fig. 4). Third, we have not tested the CTC hypothesis for oscillations in other frequency bands. In particular, oscillations in the betafrequency band $(13-30 \mathrm{~Hz})$ play important roles in human sensorimotor cortex, for example, during maintenance of tonic motor output or at rest (Pfurtscheller and Lopes da Silva, 1999; Baker, 2007). Furthermore, interhemispheric synchronization during bimanual and unimanual motor tasks was observed in monkey motor cortex for activity in the beta-frequency band (Murthy and Fetz, 1996). Therefore, future experiments should test the effects of interhemispheric phase synchronization of sensorimotor beta-oscillations on SIHI during rest and motor tasks. Fourth, slight repositioning and reorienting of the conditioning coil was necessary in most of the subjects to fit both coils tangentially on the scalp. This likely explained the moderated $\mu$-phasedependent effect on conditioning compared with test MEP amplitude (see Results), but may also have led to a suboptimal performance and thus underestimation with respect to $\mu$-phase modulation of SIHI. Future experiments could use smaller stimulating coils to address this issue.

In conclusion, this EEG-TMS study demonstrates that interhemispheric phase synchronicity of the two sensorimotor cortices at the negative peak of the endogenous $\mu$-rhythm, a high-excitability state, was associated with optimal effective interhemispheric motor connectivity, as indexed by maximal short-interval interhemispheric inhibition measured in a pairedcoil TMS protocol. Our findings support the notion that temporal dynamics of neuronal oscillations in reciprocal neuronal networks significantly affect large-scale interhemispheric network communication, consistent with the theory of communication through coherence.

\section{References}

Avenanti A, Coccia M, Ladavas E, Provinciali L, Ceravolo MG (2012) Lowfrequency rTMS promotes use-dependent motor plasticity in chronic stroke: a randomized trial. Neurology 78:256-264. CrossRef Medline

Baker SN (2007) Oscillatory interactions between sensorimotor cortex and the periphery. Curr Opin Neurobiol 17:649-655. CrossRef Medline

Boddington LJ, Reynolds JNJ (2017) Targeting interhemispheric inhibition with neuromodulation to enhance stroke rehabilitation. Brain Stimul 10: 214-222. CrossRef Medline

Bungert A, Antunes A, Espenhahn S, Thielscher A (2017) Where does TMS stimulate the motor cortex? Combining electrophysiological measurements and realistic field estimates to reveal the affected cortex position. Cereb Cortex 27:5083-5094. CrossRef Medline

Buzsáki G, Draguhn A (2004) Neuronal oscillations in cortical networks. Science 304:1926-1929. CrossRef Medline

Buzsáki G, Anastassiou CA, Koch C (2012) The origin of extracellular fields and currents-EEG, ECoG, LFP and spikes. Nat Rev Neurosci 13:407-420. CrossRef Medline

Chatrian GE, Petersen MC, Lazarte JA (1959) The blocking of the rolandic wicket rhythm and some central changes related to movement. Electroencephalogr Clin Neurophysiol 11:497-510. CrossRef Medline

Chen LL, Madhavan R, Rapoport BI, Anderson WS (2013) Real-time brain oscillation detection and phase-locked stimulation using autoregressive spectral estimation and time-series forward prediction. IEEE Trans Biomed Eng 60:753-762. CrossRef Medline

Daskalakis ZJ, Christensen BK, Fitzgerald PB, Roshan L, Chen R (2002) The mechanisms of interhemispheric inhibition in the human motor cortex. J Physiol 543:317-326. CrossRef Medline

DeFelipe J, Conley M, Jones EG (1986) Long-range focal collateralization of axons arising from corticocortical cells in monkey sensory-motor cortex. J Neurosci 6:3749-3766. CrossRef Medline

Engel AK, König P, Kreiter AK, Singer W (1991) Interhemispheric synchronization of oscillatory neuronal responses in cat visual cortex. Science 252:1177-1179. CrossRef Medline

Ferbert A, Priori A, Rothwell JC, Day BL, Colebatch JG, Marsden CD (1992) Interhemispheric inhibition of the human motor cortex. J Physiol 453: 525-546. CrossRef Medline

Florian G, Andrew C, Pfurtscheller G (1998) Do changes in coherence always reflect changes in functional coupling? Electroencephalogr Clin Neurophysiol 106:87-91. CrossRef Medline

Fries P (2005) A mechanism for cognitive dynamics: neuronal communication through neuronal coherence. Trends Cogn Sci 9:474-480. CrossRef Medline

Fries P (2015) Rhythms for cognition: communication through coherence. Neuron 88:220-235. CrossRef Medline

Ghosh S, Mehta AR, Huang G, Gunraj C, Hoque T, Saha U, Ni Z, Chen R (2013) Short and long-latency inter-hemispheric inhibition are additive in the human motor cortex. J Neurophysiol 109:2955-2962. CrossRef Medline

Gilio F, Rizzo V, Siebner HR, Rothwell JC (2003) Effects on the right motor hand-area excitability produced by low-frequency rTMS over human contralateral homologous cortex. J Physiol 551:563-573. CrossRef Medline

Grefkes C, Nowak DA, Wang LE, Dafotakis M, Eickhoff SB, Fink GR (2010) Modulating cortical connectivity in stroke patients by rTMS assessed with fMRI and dynamic causal modelling. Neuroimage 50:233-242. CrossRef Medline

Groppa S, Oliviero A, Eisen A, Quartarone A, Cohen LG, Mall V, Kaelin-Lang A, Mima T, Rossi S, Thickbroom GW, Rossini PM, Ziemann U, Valls-Solé J, Siebner HR (2012) A practical guide to diagnostic transcranial magnetic stimulation: report of an IFCN committee. Clin Neurophysiol 123: 858-882. CrossRef Medline

Haegens S, Nácher V, Luna R, Romo R, Jensen O (2011) alpha-oscillations in the monkey sensorimotor network influence discrimination performance by rhythmical inhibition of neuronal spiking. Proc Natl Acad Sci U S A 108:19377-19382. CrossRef Medline

Hallett M (2007) Transcranial magnetic stimulation: a primer. Neuron 55: 187-199. CrossRef Medline

Hari R (2006) Action-perception connection and the cortical mu rhythm. Prog Brain Res 159:253-260. CrossRef Medline

Hjorth B (1975) An on-line transformation of EEG scalp potentials into 
orthogonal source derivations. Electroencephalogr Clin Neurophysiol 39: 526-530. CrossRef Medline

Hyvärinen A, Ramkumar P, Parkkonen L, Hari R (2010) Independent component analysis of short-time fourier transforms for spontaneous EEG/ MEG analysis. Neuroimage 49:257-271. CrossRef Medline

Innocenti GM (1986) General organization of the callosal connections in the cerebral cortex. In: Cerebral cortex (Jones EG, Peters A, eds), pp 291-353. New York: Plenum.

Jensen O, Mazaheri A (2010) Shaping functional architecture by oscillatory alpha activity: gating by inhibition. Front Hum Neurosci 4:186. CrossRef Medline

Jones EG, Wise SP (1977) Size, laminar and columnar distribution of efferent cells in the sensory-motor cortex of monkeys. J Comp Neurol 175: 391-438. CrossRef Medline

Kobayashi M, Hutchinson S, Schlaug G, Pascual-Leone A (2003) Ipsilateral motor cortex activation on functional magnetic resonance imaging during unilateral hand movements is related to interhemispheric interactions. Neuroimage 20:2259-2270. CrossRef Medline

Laakso I, Hirata A, Ugawa Y (2014) Effects of coil orientation on the electric field induced by TMS over the hand motor area. Phys Med Biol 59:203218. CrossRef Medline

Laakso I, Murakami T, Hirata A, Ugawa Y (2018) Where and what TMS activates: experiments and modeling. Brain Stimul 11:166-174. CrossRef Medline

Lachaux JP, Rodriguez E, Martinerie J, Varela FJ (1999) Measuring phase synchrony in brain signals. Hum Brain Mapp 8:194-208. CrossRef Medline

Lowet E, Roberts MJ, Bonizzi P, Karel J, De Weerd P (2016) Quantifying neural oscillatory synchronization: a comparison between spectral coherence and phase-locking value approaches. PLoS One 11:e0146443. CrossRef Medline

Markram H, Toledo-Rodriguez M, Wang Y, Gupta A, Silberberg G, Wu C (2004) Interneurons of the neocortical inhibitory system. Nat Rev Neurosci 5:793-807. CrossRef Medline

McFarland DJ, Wolpaw JR (2008) Sensorimotor rhythm-based braincomputer interface (BCI): model order selection for autoregressive spectral analysis. J Neural Eng 5:155-162. CrossRef Medline

Murthy VN, Fetz EE (1996) Oscillatory activity in sensorimotor cortex of awake monkeys: synchronization of local field potentials and relation to behavior. J Neurophysiol 76:3949-3967. CrossRef Medline

Netz J, Ziemann U, Hömberg V (1995) Hemispheric asymmetry of transcallosal inhibition in man. Exp Brain Res 104:527-533. Medline

Ni Z, Gunraj C, Nelson AJ, Yeh IJ, Castillo G, Hoque T, Chen R (2009) Two phases of interhemispheric inhibition between motor related cortical areas and the primary motor cortex in human. Cereb Cortex 19:1654-1665. CrossRef Medline

Oostenveld R, Fries P, Maris E, Schoffelen JM (2011) FieldTrip: open source software for advanced analysis of MEG, EEG, and invasive electrophysiological data. Comput Intell Neurosci 2011:156869. CrossRef Medline

Pal PK, Hanajima R, Gunraj CA, Li JY, Wagle-Shukla A, Morgante F, Chen R (2005) Effect of low frequency repetitive transcranial magnetic stimula- tion on interhemispheric inhibition. J Neurophysiol 94:1668-1675. CrossRef Medline

Perrin F, Pernier J, Bertrand O, Echallier JF (1989) Spherical splines for scalp potential and current density mapping. Electroencephalogr Clin Neurophysiol 72:184-187. CrossRef Medline

Pfurtscheller G, Lopes da Silva FH (1999) Event-related EEG/MEG synchronization and desynchronization: basic principles. Clin Neurophysiol 110:1842-1857. CrossRef Medline

Picazio S, Veniero D, Ponzo V, Caltagirone C, Gross J, Thut G, Koch G (2014) Prefrontal control over motor cortex cycles at beta frequency during movement inhibition. Curr Biol 24:2940-2945. CrossRef Medline

Rossi S, Hallett M, Rossini PM, Pascual-Leone A; Safety of TMS Consensus Group (2009) Safety, ethical considerations, and application guidelines for the use of transcranial magnetic stimulation in clinical practice and research. Clin Neurophysiol 120:2008-2039. CrossRef Medline

Rossini PM et al. (2015) Non-invasive electrical and magnetic stimulation of the brain, spinal cord, roots and peripheral nerves: basic principles and procedures for routine clinical and research application. an updated report from an I.F.C.N. Committee. Clin Neurophysiol 126:1071-1107. CrossRef Medline

Salenius S, Portin K, Kajola M, Salmelin R, Hari R (1997) Cortical control of human motoneuron firing during isometric contraction. J Neurophysiol 77:3401-3405. CrossRef Medline

Seeck M, Koessler L, Bast T, Leijten F, Michel C, Baumgartner C, He B, Beniczky S (2017) The standardized EEG electrode array of the IFCN. Clin Neurophysiol 128:2070-2077. CrossRef Medline

Singer W (1999) Neuronal synchrony: a versatile code for the definition of relations? Neuron 24:49-65, 111-125. CrossRef Medline

Sjöström PJ, Turrigiano GG, Nelson SB (2001) Rate, timing, and cooperativity jointly determine cortical synaptic plasticity. Neuron 32:11491164. CrossRef Medline

Tazoe T, Endoh T, Kitamura T, Ogata T (2014) Polarity specific effects of transcranial direct current stimulation on interhemispheric inhibition. PLoS One 9:e114244. CrossRef Medline

Uhlhaas PJ, Singer W (2010) Abnormal neural oscillations and synchrony in schizophrenia. Nat Rev Neurosci 11:100-113. CrossRef Medline

Varela F, Lachaux JP, Rodriguez E, Martinerie J (2001) The brainweb: phase synchronization and large-scale integration. Nat Rev Neurosci 2:229239. CrossRef Medline

Vijayan S, Kopell NJ (2012) Thalamic model of awake alpha oscillations and implications for stimulus processing. Proc Natl Acad Sci U S A 109: 18553-18558. CrossRef Medline

Wahl M, Lauterbach-Soon B, Hattingen E, Jung P, Singer O, Volz S, Klein JC, Steinmetz H, Ziemann U (2007) Human motor corpus callosum: topography, somatotopy, and link between microstructure and function. J Neurosci 27:12132-12138. CrossRef Medline

Womelsdorf T, Schoffelen JM, Oostenveld R, Singer W, Desimone R, Engel AK, Fries P (2007) Modulation of neuronal interactions through neuronal synchronization. Science 316:1609-1612. CrossRef Medline

Zrenner C, Desideri D, Belardinelli P, Ziemann U (2018) Real-time EEGdefined excitability states determine efficacy of TMS-induced plasticity in human motor cortex. Brain Stimul 11:374-389. CrossRef Medline 